\title{
Does the prescriptive lifestyle of Seventh-day Adventists provide 'immunity' from the secular effects of changes in BMI?
}

\author{
Lillian M Kent ${ }^{1, *}$ and Anthony Worsley ${ }^{2}$ \\ 'Deakin University, School of Exercise and Nutrition Sciences, Faculty of Health and Behavioral Sciences, 221 \\ Burwood Highway, Burwood, Melbourne, Victoria 3125, Australia: ${ }^{2}$ VicHealth, Melbourne, Victoria, Australia
}

Submitted 21 August 2007: Accepted 6 March 2008: First published online 6 May 2008

\begin{abstract}
Objective: To examine the effect of Seventh-day Adventist (SDA) membership on 'immunity' to the secular effects of changes in BMI.

Design: Three independent, cross-sectional, screening surveys conducted by Sydney Adventist Hospital in 1976, 1986 and 1988 and a survey conducted among residents of Melbourne in 2006.

Subjects: Two hundred and fifty-two SDA and 464 non-SDA in 1976; 166 SDA and 291 non-SDA in 1986; 120 SDA and 300-non SDA in 1988; and 251 SDA and 294 non-SDA in 2006.

Measurements: Height and weight measured by hospital staff in 1976, 1986 and 1988; self-reported by respondents in 2006.

Results: The mean BMI of non-SDA men increased between 1986 and 2006 $(P<0 \cdot 001)$ but did not change for SDA men or non-SDA women. Despite small increases in SDA women's mean BMI $(P=0 \cdot 030)$ between 1988 and 2006, this was no different to that of SDA men and non-SDA women in 2006. The diet and eating patterns of SDA men and women were more 'prudent' than those of nonSDA men and women, including more fruit, vegetables, grains, nuts and legumes, and less alcohol, meat, sweetened drinks and coffee. Many of these factors were found to be predictors of lower BMI.

Conclusion: The 'prudent' dietary and lifestyle prescriptions of SDA men appear to have 'immunised' them to the secular effects of changes that occurred among non-SDA men's BMI. The dietary and lifestyle trends of SDA women did not reflect the increase in their BMI observed in 2006.
\end{abstract}

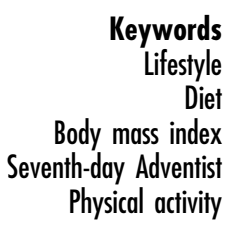

Lifestyle

Diet

Phys Adventist

Physical activity
The burden from 'lifestyle diseases' is rising rapidly and represents one of the major health challenges worldwide. However, the development of many, if not all, of the 'lifestyle diseases' is attributed to overweight and obesity $^{(1)}$. Furthermore, obesity is the most obvious manifestation of the global epidemic of sedentary lifestyles and excessive energy intake ${ }^{(2)}$. The prevalence of obesity is reaching epidemic proportions in both developed and developing countries. In Australia, the prevalence of overweight in the adult population is $60 \%$ (67\% for males and $52 \%$ for females) and $21 \%$ for obesity (22\% females and $19 \%$ males), having risen from $8 \%, 20$ years earlier ${ }^{(2)}$. This increase poses major concerns in terms of health and the economy ${ }^{(3)}$.

Although several food and physical activity factors have been implicated in the development of overweight and obesity, little is known about the role of people's eating patterns or food consumption behaviours in relation to diets. The traditional dietary patterns of many cultures often meet current dietary guidelines and can serve as a means of examining the effects of specific dietary patterns in the prevention and management of patients with chronic disease and as models for dietary improvement. The Seventh-day Adventist (SDA) diet, formed as a basis of religious beliefs, is an example of a notable dietary tradition that has been studied for its relationship between food consumption and chronic disease.

SDA live in countries where lifestyle diseases are prevalent yet they appear to enjoy low disease rates (e.g. CVD, cancer and total mortality) and unusually good health ${ }^{(4)}$. They are a conservative religious group first organised as a denomination in 1863 in the eastern USA, but Seventh-day Adventism has now become a worldwide religion with more than 13 million members ${ }^{(5)}$. In that same year, SDA 'also began to emphasise the role of lifestyle in promoting health, happiness and enhanced spirituality'; not as a measure of virtue but as a valuable spiritual discipline ${ }^{(5)}$. SDA lifestyle prescriptions prohibit the use of alcohol and tobacco and the consumption of 
biblically unclean foods such as pork and shellfish. The church does, however, recommend a vegetarian diet with regular exercise and the avoidance of tea, coffee and other caffeine-containing beverages, rich and highly refined foods, and hot condiments and spices ${ }^{(5)}$.

Although the health of SDA has been studied since 1960, there have been limited studies that directly compare health outcomes for SDA and non-SDA ${ }^{(6-9)}$. The aims of the present study were therefore to examine the effect of SDA membership on 'immunity' to the secular effects of changes in BMI and to investigate the changes in diet and lifestyle of SDA and non-SDA between 1976 and 2006.

\section{Methods}

\section{Participants}

Between 1976 and 1990, residents of the general community around the Sydney Adventist Hospital (SAH) were invited to take part in heart health screening surveys that assessed heart health, food consumption and other lifestyle practices. Samples were randomly selected from these surveys for every biennial year from 1976 to 1990. These biennial samples were selected to examine changes in BMI. However, due to insufficient numbers of SDA, only data for 1976, 1986 and 1988 were examined. Each year's sample comprised a different set of individuals. Although the hospital continued to collect data after 1990, no information on religious affiliation was included and so data post-1990 were not available for the present study. As a result, the authors conducted another study in 2006. Melbourne was selected as the site of the survey. The Socio-Economic Indices For Areas (SEIFA) relative socio-economic disadvantage score for the area $\mathrm{SAH}$ services was $1095 \cdot 03$ in 2001. As all Australian capital cities have SEIFA scores $>1087$, using a Melbourne sample in place of a sample from New South Wales was convenient and valid ${ }^{(10)}$. Questionnaires, consent forms and reply-paid envelopes were sent out to 1000 individuals randomly selected from the Melbourne White Pages Telephone Directory. The response rate was $37 \%$. In addition, 500 surveys were distributed in person to SDA via church gatherings, schools and administration facilities. The SDA response rate was $50 \%$.

As well as the examination of changes in BMI, two SAH years (10 years apart: 1976, 1986; 1996 not available due to lack of demographic data) and 2006 were selected to examine changes in diet and lifestyle and to determine which behaviours predict BMI for the two groups. Respondents were older and better educated than the general population in all years examined (except 1986, which was younger than the general population).

Respondents were asked to complete a questionnaire that included an FFQ and queried about the frequency of various moderate and vigorous physical activities, dietary habits, smoking and alcohol usage and lifestyle behaviours.

\section{FFQ}

Forty-two different foods and drinks, ranging from a variety of meats, cheeses, milks, sweets, desserts, sweet drinks, alcoholic drinks, tea, coffee, spreads, salad dressings, vegetables, fruit, cereals and breads, were included in the 1976 questionnaire. Dietary practices included 'relative breakfast size', 'dieting to lose weight' and frequency of 'cut fat from meat', 'eat between meals' and 'add salt at table'. These foods and dietary practices were replicated in the 1986 questionnaire, with the addition of fish and cream. The 2006 questionnaire included more than seventy foods and drinks and comprised variables from previous years as well as takeaway foods, refined grains $v$. whole grains, legumes, nuts, low-energy drinks, water, yoghurt, decaffeinated drinks and various breakfast foods. All categorical variables were converted to continuous variables to determine the midpoint of the range for each category. Variables consumed on a daily basis were converted to weekly consumption by multiplying the midpoint value by seven.

\section{Physical activity}

This portion of the questionnaire was similar for 1976 and 1986 in terms of frequency of the activities of walking, running, cycling, swimming, tennis, vigorous gardening and other vigorous activity. However in 1986, the questionnaire sought responses only if each activity was engaged in for more than $20 \mathrm{~min}$. These categorical variables were converted to continuous variables by determining the midpoint of the range for each category (similar to the FFQ conversion). Due to these differences, the 1999 Australian National Physical Activity Survey was incorporated into the 2006 questionnaire ${ }^{(11)}$. Variables related to frequency and duration (minutes) of walking, moderate and vigorous physical activity. 'Sufficient' physical activity was calculated by: (i) 'sufficient' time $\geq 150 \mathrm{~min} /$ week $=$ total minutes spent in walking and other moderate physical activity, plus twice the minutes in vigorous activity; and (ii) 'sufficient' physical activity $\geq 150 \mathrm{~min} /$ week and sessions $\geq 5 /$ week $=$ as above, however the $\geq 150 \mathrm{~min} /$ week must be accumulated in at least five separate sessions (i.e. by summing the frequency items). In addition, each individual physical activity variable (walking, vigorous physical activity and moderate physical activity) was examined.

\section{Otber lifestyle factors}

Other lifestyle factors examined included hours of sleep per night, smoking status (current, past and never smoked), frequency of alcohol consumption and number of drinks consumed per sitting. 


\section{BMI}

Height and weight used to determine BMI were measured objectively by SAH staff. In 2006, respondents were asked to measure and record two height and weight measurements. BMI $\left(\mathrm{kg} / \mathrm{m}^{2}\right)$ was calculated as weight (in kilograms) divided by the square of height (in metres).

\section{Data analysis}

A one-way, between-groups analysis of covariance (ANCOVA) was conducted to compare the changes in BMI between 1976 and 2006, with age as the covariate. Bivariate analyses were conducted to examine the relationships between respondents' BMI and a series of variables that have been associated with BMI in the literature, including age, sex, education, occupation status, marital status, food consumption variables and eating habits. Pearson's correlation was used to assess relationships between BMI and continuous variables. Spearman's rank-order correlation, using two-tailed tests of significance, was used to examine relationships between nominal or ordinal variables and BMI. Those variables that were significantly related to BMI were subsequently entered into a multiple regression analysis of BMI (one analysis for each survey year). Data were analysed using the Statistical Package for the Social Sciences statistical software package version $12 \cdot 0$ (SPSS Inc., Chicago, IL, USA).

\section{Results}

Age

Table 1 shows large variations in mean age between SDA and non-SDA men and women, particularly in 1986 and 1988. This table also shows larger standard errors of the

Table 1 Age comparison (independent $t$ test) of the samples of Seventh-day Adventists (SDA) and non-SDA studied in the present analysis

\begin{tabular}{|c|c|c|c|c|c|c|c|}
\hline & & \multirow[b]{3}{*}{$n$} & \multicolumn{2}{|c|}{ Men } & \multirow[b]{3}{*}{$n$} & \multicolumn{2}{|c|}{ Women } \\
\hline & & & \multicolumn{2}{|c|}{ Age (years) } & & \multicolumn{2}{|c|}{ Age (years) } \\
\hline & & & Mean & SE & & Mean & $\mathrm{SE}$ \\
\hline \multirow[t]{4}{*}{1976} & SDA & 133 & $44 \cdot 33$ & $1 \cdot 220$ & 119 & $45 \cdot 75$ & $1 \cdot 427$ \\
\hline & Non-SDA & 247 & $44 \cdot 63$ & $0 \cdot 742$ & 217 & $45 \cdot 98$ & 0.853 \\
\hline & & & \multirow{2}{*}{\multicolumn{2}{|c|}{0.206}} & & \multicolumn{2}{|c|}{0.134} \\
\hline & $P$ & & & & & \multicolumn{2}{|c|}{0.894} \\
\hline \multirow{4}{*}{1986} & SDA & 75 & $42 \cdot 13$ & $1 \cdot 744$ & 91 & $35 \cdot 46$ & 1.823 \\
\hline & Non-SDA & 163 & $46 \cdot 51$ & $0 \cdot 860$ & 128 & $50 \cdot 51$ & 1.029 \\
\hline & $t$ & & \multicolumn{2}{|c|}{$2 \cdot 250$} & & \multicolumn{2}{|c|}{$7 \cdot 187$} \\
\hline & $P$ & & \multicolumn{2}{|c|}{0.026} & & \multicolumn{2}{|c|}{$<0.001$} \\
\hline \multirow[t]{4}{*}{1988} & SDA & 43 & 28.98 & $2 \cdot 439$ & 77 & $32 \cdot 45$ & $1 \cdot 883$ \\
\hline & Non-SDA & 155 & $52 \cdot 01$ & 0.986 & 145 & $49 \cdot 27$ & 0.985 \\
\hline & & & \multirow{2}{*}{\multicolumn{2}{|c|}{$\begin{array}{r}8.756 \\
-0.001\end{array}$}} & & \multicolumn{2}{|c|}{$7 \cdot 911$} \\
\hline & $P$ & & & & & $<0$ & 001 \\
\hline \multirow[t]{4}{*}{2006} & SDA & 118 & $51 \cdot 63$ & $1 \cdot 595$ & 133 & $51 \cdot 29$ & $1 \cdot 357$ \\
\hline & Non-SDA & 120 & & 1.437 & 174 & $48 \cdot 68$ & $1 \cdot 131$ \\
\hline & $t$ & & \multicolumn{2}{|c|}{1.987} & & \multicolumn{2}{|c|}{$-1 \cdot 485$} \\
\hline & $P$ & & \multicolumn{2}{|c|}{0.048} & & \multicolumn{2}{|c|}{$0 \cdot 139$} \\
\hline
\end{tabular}

mean within the SDA group compared with non-SDA in 1986, 1988 and 2006.

\section{Trends in mean BMI}

After adjusting for age, there was no significant difference in mean BMI between 1976, 1987, 1988 and 2006 for SDA men $\left(F(3,358)=0 \cdot 625, P=0.599\right.$, partial $\left.\eta^{2}=0 \cdot 005\right)$ (Fig. 1). There was, however, a statistically significant difference in mean BMI between the four years for non-SDA men $(F(3,684)=6 \cdot 782, \quad P<0 \cdot 001$, partial $\left.\eta^{2}=0 \cdot 029\right)$. Post hoc comparisons using the Tukey HSD test indicated that the mean BMI for $1976(25 \cdot 57$ (SE 0 18) $\left.\mathrm{kg} / \mathrm{m}^{2}\right)$ was significantly lower $(P=0 \cdot 002)$ than in 2006 $\left(26.97(\mathrm{sE} 0.48) \mathrm{kg} / \mathrm{m}^{2}\right)$ and the mean BMI for $1986(24.96$ $(\mathrm{sE} 0 \cdot 24) \mathrm{kg} / \mathrm{m}^{2}$ ) was significantly lower than in 1988 $(P=0 \cdot 004$, mean 26.24 (sE $\left.0 \cdot 41) \mathrm{kg} / \mathrm{m}^{2}\right)$ and 2006 $(P<0 \cdot 001)$ (Fig. 1). In addition, the mean BMI of SDA men was significantly lower than that of non-SDA men in $1976\left(F(1,376)=9 \cdot 881, \quad P=0 \cdot 002\right.$, partial $\left.\eta^{2}=0.026\right)$ after adjusting for age $(F=26 \cdot 860, P<0 \cdot 001)$, in 1986 $\left(F(1,230)=3.922, \quad P=0.049\right.$, partial $\left.\eta^{2}=0.017\right)$ after adjusting for age $(F=6.041, \quad P=0.015), \quad$ in 1988 $\left(F(1,196)=10 \cdot 341, P=0 \cdot 002\right.$, partial $\left.\eta^{2}=0 \cdot 050\right)$ with no age adjustment, and in $2006(F(1,235)=6 \cdot 974, P=0 \cdot 009$, partial $\left.\eta^{2}=0 \cdot 029\right)$ with no age adjustment (Fig. 1).

On the other hand, no significant differences in mean BMI between the four years was found for non-SDA women $\left(F(3,662)=1 \cdot 814, P=0.143\right.$, partial $\left.\eta^{2}=0.008\right)$ (Fig. 2). Although the ANCOVA for SDA women's BMI showed no significant differences $(F(3,417)=1.944$, $P=0 \cdot 122$, partial $\left.\eta^{2}=0 \cdot 014\right)$, the mean BMI in 2006 $(24.95$ (sE 0.37$\left.) \quad \mathrm{kg} / \mathrm{m}^{2}\right)$ was significantly higher $(P=0 \cdot 030)$ than in $1976\left(23 \cdot 80(\right.$ SE $\left.0 \cdot 38) \mathrm{kg} / \mathrm{m}^{2}\right)$ (Fig. 2). Despite this increase the BMI of SDA women in 2006 was not significantly different to that of non-SDA women $\left(F(1,301)=2.947, \quad P=0.087\right.$, partial $\left.\eta^{2}=0.010\right)$ after adjusting for age $(F=12 \cdot 093, P=0 \cdot 001)$, a finding also observed in previous years.

\section{Antecedents of BMI between 1976 and 2006}

The predictors of BMI differed for SDA and non-SDA men, except for age, dieting to lose weight, eating

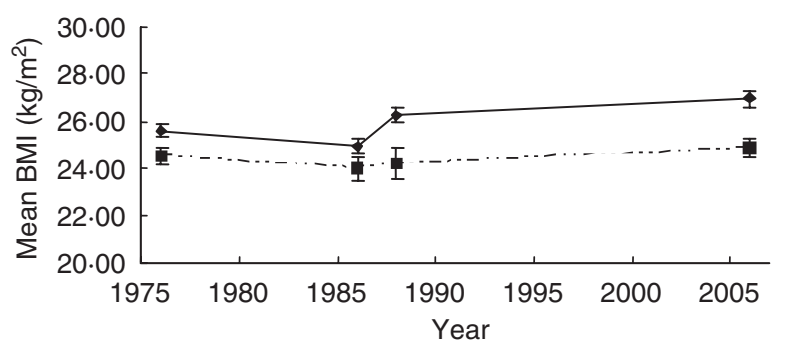

Fig. 1 Differences in Seventh-day Adventist (SDA; - $\mathbf{-} \cdot-$ ) and non-SDA (- -) men's BMI in 1976, 1986, 1988 and 2006. Values are means with their standard errors represented by vertical bars. After adjusting for age: SDA men $(F=13 \cdot 496$, $P<0.001$ ) and non-SDA men (NS) 


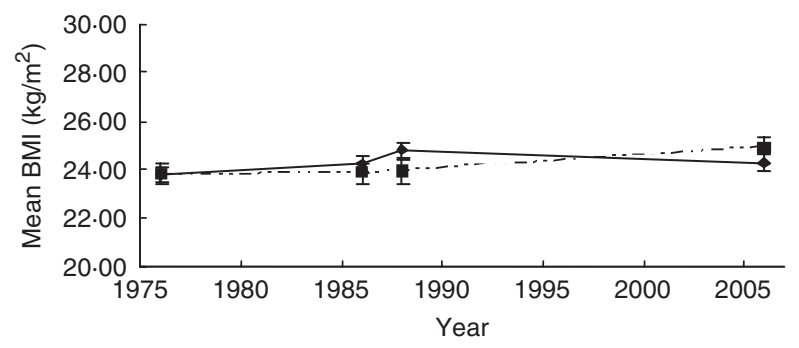

Fig. 2 Differences in Seventh-day Adventist (SDA; - $\mathbf{-}$. - -) and non-SDA (- -) women's BMI in 1976, 1986, 1988 and 2006. Values are means with their standard errors represented by vertical bars. After adjusting for age: non-SDA women $(F=14.575, \quad P<0.001)$ and SDA women $(F=11.581$, $P<0.001)$

between meals and frequency of consumption of chicken (Table 2). Although found to be predictors of BMI in both groups, eating between meals and frequency of vigorous physical activity were differentially related to BMI for SDA and non-SDA men (Table 2). For SDA men, frequent eating between meals predicted increases in BMI while more frequent physical activity predicted decreases in BMI (Table 2). Conversely, non-SDA men who ate once or twice between meals each day had lower BMI than those who never or more frequently ate between meals (Table 2). Furthermore, frequency of vigorous physical activity was positively associated with BMI among non-SDA men (Table 2). Nevertheless, the factors that predicted increases in BMI included age, dieting to lose weight, eating between meals, consumption of meat, lowfat milk, low-energy soft drinks and extra foods (pie and cake, coffee and hot chocolate) (Table 2). On the other hand, factors that predicted decreases in BMI included food variety, regular meals, breakfast, fruit, tea, spreads, legumes and physical activity (Table 2). For men, the larger the reported breakfast consumed the lower their BMI.

The predictors of BMI differed for SDA and non-SDA women, except dieting to lose weight (Table 3). Even so, the factors that predicted increases in BMI for women included age, dieting to lose weight, eating between meals, table salt use and consumption of meat, whole milk and extra foods (soft drinks and low-energy soft drinks, cola, sugar, pizza, margarine) (Table 3). In contrast, factors that predicted decreases in BMI for women in 1986 included consumption of soya milk and spreads, and physical activity (Table 3).

\section{Trends in diet and lifestyle factors between 1976 and 2006}

Although vegetables, fruit, grains (including bread, cereals and rice), extra foods and moderate to large breakfasts were consumed by a smaller proportion of SDA and non-SDA men in 2006 than in previous years, these foods (except extra foods) together with soya milk, legumes and spreads were consumed by a greater proportion of SDA men than non-SDA men (Figs 3 and 4). In addition, the proportion of non-SDA men who consumed low-fat milk increased in 2006 while the proportion of SDA men did not change between 1986 and 2006. Furthermore, the proportion of SDA men who consumed alcohol, tea and meat and ate between meals (coffee did not change) increased, while the proportion of non-SDA men who consumed alcohol, tea and coffee (meat and eating between meals did not change) decreased (Figs 3 and 4). Despite these changes, a smaller proportion of SDA men consumed meat, alcohol, extra foods, low-fat milk, coffee and tea than non-SDA men (Figs 3 and 4). Soya milk, legumes, rice, fruit, spreads and vegetarianism predicted lower BMI in the present study, whereas low-fat milk, meat, alcohol, sweetened drinks and coffee predicted higher BMI. These differences may have contributed to the lower BMI and proportion of overweight and obese SDA men ( $40 \%$ in 2006) compared with non-SDA men (65\% in 2006), supporting the hypothesis that SDA men are more resistant to changes in diet and lifestyle than non-SDA men.

The changes observed for men were also found for women in both groups except for tea (no change for SDA women) and substantial breakfast (already low in both groups) (figures available upon request from the corresponding author). Unlike men though, the differences between the women were not as prolific. In 2006, a greater proportion of SDA women consumed soya milk, vegetables, fruit and were vegetarian, while a smaller proportion consumed legumes, low-fat milk, meat, alcohol, sweetened drinks (except soft drink), coffee and tea than non-SDA women. All other foods were consumed by similar proportions of SDA and non-SDA women.

However, a greater share of SDA women than men were vegetarian, consumed butter, fruit and vegetables, while a smaller proportion consumed desserts, takeaway foods, meat and cola. Conversely, SDA men consumed grains more frequently than SDA women. These results show a disparity between diet and BMI, and proportion of overweight and obese SDA men ( $41 \%$ ) and women (42\%). Figure 2 shows that the mean BMI of SDA women increased marginally between 1988 and 2006. No significant increase was observed for SDA men.

On the other hand, a greater proportion of non-SDA men than women consumed extra foods (in particular takeaway foods, sweetened drinks, flavoured milk, alcohol and margarine), while a smaller proportion consumed vegetables, soya milk, legumes, grains and butter. These differences may have contributed to the higher BMI and the greater proportion of overweight and obese respondents among non-SDA men than women (65\% compared with $34 \%$ ). 


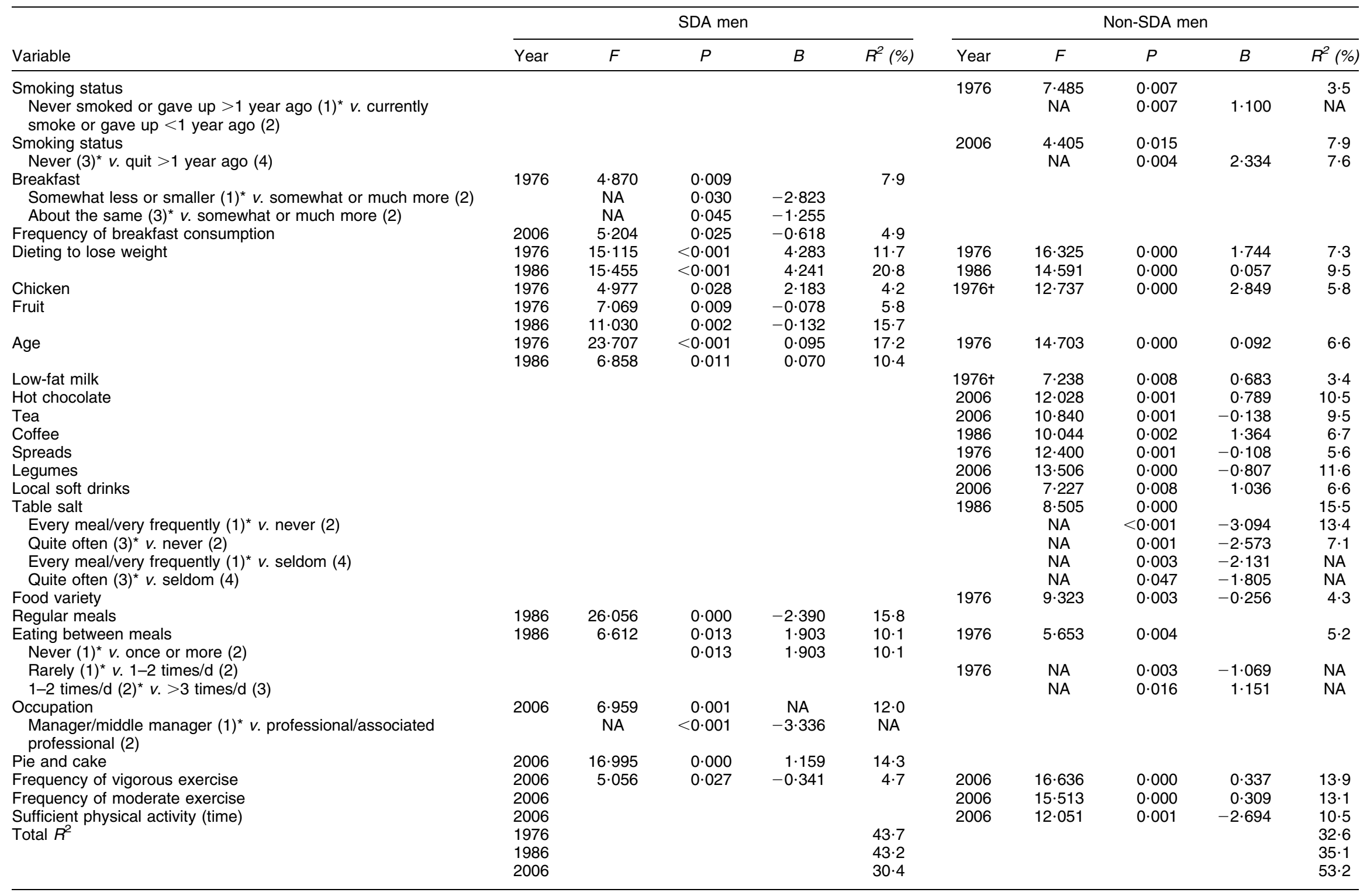

$P$, significance; $R^{2}$, partial $\eta^{2} ; \mathrm{NA}$, not available.

( ) refers to number in cell. Non-SDA smoking status 1976 and 2006: $(1)=173 ;(2)=47 ;(3)=60 ;(4)=38$. SDA breakfast 1976: (1) $=20 ;(2)=34 ;(3)=67$. Non-SDA

*Distinguishes categories with significant differences.

tInteraction with age (chicken positively associated with BMI among <45-year-olds and low-fat milk positively associated with BMI among 25-34-year-olds). 
Table 3 Statistically significant demographic, food and lifestyle predictors or associates of BMI in 1976, 1986 and 2006 among Seventh-day Adventist (SDA) women and non-SDA women

\begin{tabular}{|c|c|c|c|c|c|c|c|c|c|c|}
\hline \multirow[b]{2}{*}{ Variable } & \multicolumn{5}{|c|}{ SDA women } & \multicolumn{5}{|c|}{ Non SDA women } \\
\hline & Year & $F$ & $P$ & $B$ & $R^{2}(\%)$ & Year & $F$ & $P$ & $B$ & $R^{2}(\%)$ \\
\hline Chicken & 1976 & $10 \cdot 862$ & 0.001 & $1 \cdot 774$ & $9 \cdot 0$ & & & & & \\
\hline Cola & & & & & & 1986 & $5 \cdot 538$ & 0.020 & $1 \cdot 791$ & 4.9 \\
\hline Soft drinks & 1976 & $7 \cdot 656$ & 0.007 & $0 \cdot 736$ & $6 \cdot 5$ & & & & & \\
\hline Low-energy soft drinks & & & & & & 2006 & $5 \cdot 455$ & 0.023 & $0 \cdot 806$ & $8 \cdot 0$ \\
\hline Whole milk & 1976 & $7 \cdot 996$ & 0.006 & $-0 \cdot 109$ & $6 \cdot 8$ & 1986 & $4 \cdot 829$ & 0.030 & $0 \cdot 120$ & $4 \cdot 3$ \\
\hline Soya milk & & & & & & $1976+$ & $4 \cdot 598$ & 0.033 & $-10 \cdot 312$ & $2 \cdot 4$ \\
\hline Wieners & 1986 & $7 \cdot 881$ & 0.006 & $11 \cdot 711$ & $8 \cdot 5$ & & & & & \\
\hline Spreads & 1986 & $10 \cdot 307$ & 0.002 & -0.335 & $10 \cdot 8$ & & & & & \\
\hline Age & 1986 & $7 \cdot 514$ & 0.007 & 0.076 & $8 \cdot 1$ & $\begin{array}{l}1976 \\
2006\end{array}$ & $\begin{array}{l}21 \cdot 899 \\
21 \cdot 502\end{array}$ & $\begin{array}{r}0.000 \\
<0.001\end{array}$ & $\begin{array}{l}0.081 \\
0.122\end{array}$ & $\begin{array}{l}10 \cdot 3 \\
25 \cdot 4\end{array}$ \\
\hline Added sugar & 2006 & $17 \cdot 219$ & 0.000 & $1 \cdot 415$ & $12 \cdot 2$ & & & & & \\
\hline Margarine & & & & & & 1986 & $6 \cdot 440$ & 0.013 & 0.061 & $5 \cdot 7$ \\
\hline Bread rolls & 2006 & $5 \cdot 467$ & 0.021 & 0.469 & $4 \cdot 2$ & & & & & \\
\hline Dieting & 2006 & $20 \cdot 907$ & 0.000 & $5 \cdot 848$ & $14 \cdot 4$ & $\begin{array}{l}1976 \\
1986\end{array}$ & $\begin{array}{l}35 \cdot 594 \\
27 \cdot 438\end{array}$ & $\begin{array}{r}0.000 \\
<0.000\end{array}$ & $\begin{array}{l}2 \cdot 698 \\
3 \cdot 837\end{array}$ & $\begin{array}{l}15 \cdot 8 \\
20 \cdot 4\end{array}$ \\
\hline Pizza & 2006 & $11 \cdot 591$ & 0.001 & $5 \cdot 860$ & $8 \cdot 5$ & & & & & \\
\hline $\begin{array}{l}\text { Eating between meals } \\
\text { Rarely }(1)^{\star} v .1-2 \text { times/d (2) }\end{array}$ & & & & & & 1976 & $\begin{array}{l}3 \cdot 121 \\
\mathrm{NA}\end{array}$ & 0.046 & $\begin{array}{l}\text { NA } \\
1 \cdot 220\end{array}$ & $\begin{array}{l}3 \cdot 2 \\
N A\end{array}$ \\
\hline $\begin{array}{l}\text { Rarely }(1)^{\star} v .>3 \text { times/d (3) } \\
\text { Table salt }\end{array}$ & & & & & & 1986 & $\begin{array}{l}\text { NA } \\
7 \cdot 249\end{array}$ & $\begin{array}{l}0.034 \\
0.001\end{array}$ & $1 \cdot 295$ & $\begin{array}{l}N A \\
11 \cdot 9\end{array}$ \\
\hline Seldom $(1)^{*} v$. never $(2)$ & & & & & & & & $<0.001$ & $-2 \cdot 959$ & $11 \cdot 9$ \\
\hline Quite often/more regularly $(3)^{\star} v$. seldom (1) & & & & & & & & 0.059 & 1.593 & NA \\
\hline Time in vigorous exercise & & & & & & 2006 & $4 \cdot 852$ & 0.031 & -0.007 & $7 \cdot 2$ \\
\hline Total $R^{2}$ & 1976 & & & & $24 \cdot 7$ & & & & & $26 \cdot 0$ \\
\hline & 1986 & & & & $21 \cdot 2$ & & & & & $34 \cdot 4$ \\
\hline & 2006 & & & & $36 \cdot 2$ & & & & & $34 \cdot 0$ \\
\hline
\end{tabular}

$P$, significance; $R^{2}$, partial $\eta^{2} ; \mathrm{NA}$, not available.

( ) refers to number in cell. Non-SDA eating between meals 1976: $(1)=48 ;(2)=110 ;(3)=57$. Non-SDA table salt 1986: (1) = $37 ;(2)=44 ;(3)=33$.

*Distinguishes categories with significant differences.

tPositive interaction between soya milk and age.

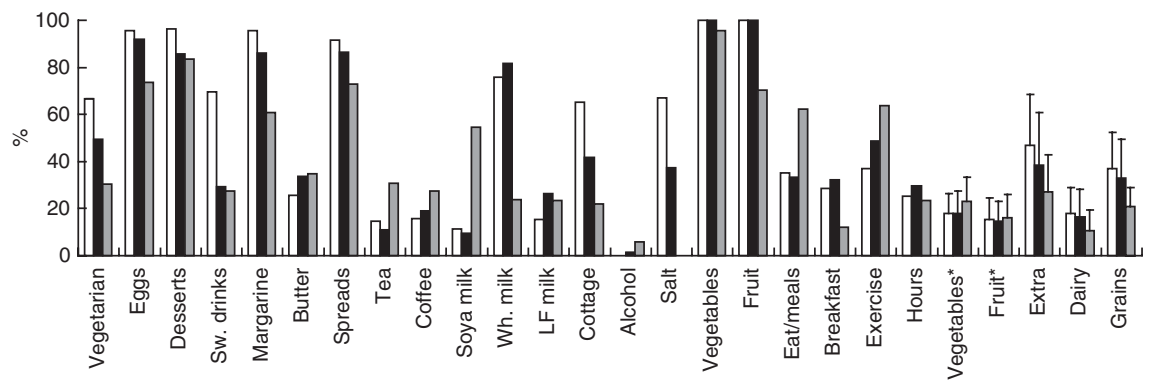

Fig. 3 Changes in food consumption and other lifestyle patterns between 1976 and 2006 ( $\square, 1976$; $\mathbf{\square}, 1986$; $\square, 2006)$ for Seventh-day Adventist men. Figure shows proportions unless indicated otherwise in the following. 'Vegetarian' refers to no meat consumption; 'Desserts' refers sweet foods (pie, cake, pastries, pudding, jelly, ice cream, cream, lollies, chocolate); 'Sw. drinks' refers to cola, soft drinks, cordial, fruit juice; 'Wh. milk' refers to whole milk; 'LF milk' refers to low-fat milk; 'Salt' refers to table salt; all other foods are as the names suggest. 'Eat/meals' refers to eating between meals; 'Breakfast' refers to the consumption of a relatively large breakfast (comprising a bowl of cereal, a serving of fruit or juice, a cup of milk and a slice of toast with spread); 'Exercise' refers to physical activity on $5 \mathrm{~d} /$ week; 'Hours' refers to more than $55 \mathrm{~h}$ spent at work/week. Using the same numeric scale, the last five categories with error bars refer to the weekly consumption frequency of the core food groups (error bars represent standard deviation). 'Vegetables"' refers to frequency of consumption of unspecified vegetables and low-fat prepared potatoes (e.g. boiled, steamed, mashed); 'Fruit"' refers to frequency of consumption of unspecified fruit; 'Extra' refers to frequency of consumption of extra foods (pie and cake, pastries, biscuits, pudding, ice cream, cream, takeaway foods, butter, margarine, tea, coffee, hot chocolate, flavoured milk, cola drinks, spreads); 'Dairy' refers to frequency of consumption of milk, cheese and yoghurt; and 'Grains' refers to frequency of consumption of bread, cereals, muffins, crackers, rice and pasta

\section{Discussion}

When SDA were compared with non-SDA over the period examined, differences were found among men but not women. The SDA prescriptions appear to have better protected SDA men from the changes that contributed to the increase in overweight and obesity among non-SDA men during the onset of the epidemic in the mid to late 1980s.

A vegetarian diet is recommended by the SDA church. Consequently, the BMI of SDA men may have been lower 


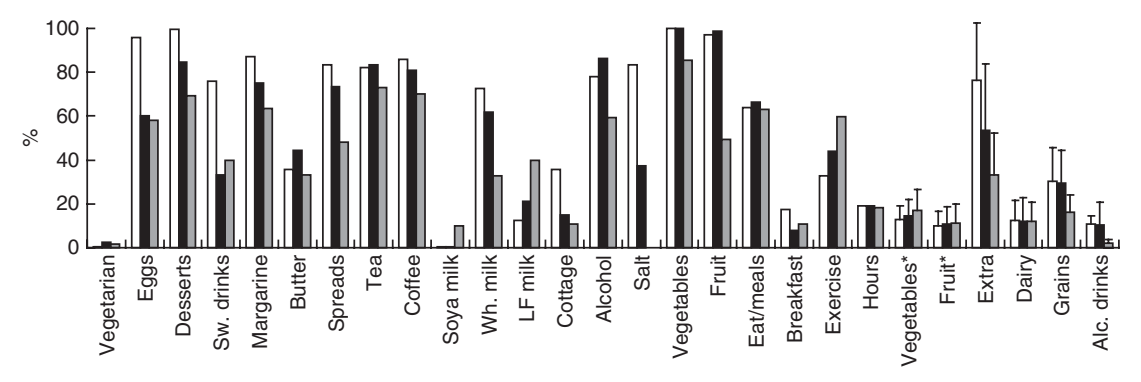

Fig. 4 Changes in food consumption and other lifestyle patterns between 1976 and 2006 ( $\square, 1976$; $\mathbf{0}, 1986$; $\square$, 2006) for non Seventh-day Adventist men. Figure shows proportions unless indicated otherwise in the following. 'Vegetarian' refers to no meat consumption; 'Desserts' refers sweet foods (pie, cake, pastries, pudding, jelly, ice cream, cream, lollies, chocolate); 'Sw. drinks' refers to cola, soft drinks, cordial, fruit juice; 'Wh. milk' refers to whole milk; 'LF milk' refers to low-fat milk; 'Salt' refers to table salt; all other foods are as the names suggest. 'Eat/meals' refers to eating between meals; 'Breakfast' refers to the consumption of a relatively large breakfast (comprising a bowl of cereal, a serving of fruit or juice, a cup of milk and a slice of toast with spread); 'Exercise' refers to physical activity on $5 \mathrm{~d}$ /week; 'Hours' refers to more than $55 \mathrm{~h}$ spent at work/week. Using the same numeric scale, the last six categories with error bars refer to the weekly consumption frequency of the core food groups plus alcoholic drinks (error bars represent standard deviation). 'Vegetables"' refers to frequency of consumption of unspecified vegetables and low-fat prepared potatoes (e.g. boiled, steamed, mashed); 'Fruit'” refers to frequency of consumption of unspecified fruit; 'Extra' refers to frequency of consumption of extra foods (pie and cake, pastries, biscuits, pudding, ice cream, cream, takeaway foods, butter, margarine, tea, coffee, hot chocolate, flavoured milk, cola drinks, spreads); 'Dairy' refers to frequency of consumption of milk, cheese and yoghurt; 'Grains' refers to frequency of consumption of bread, cereals, muffins, crackers, rice and pasta; and 'Alc. drinks' refers to frequency of consumption of beer, wine and liquor.

than that of non-SDA men because there was a greater prevalence of vegetarians among them; vegetarians tend to have lower BMI than non-vegetarians ${ }^{(12-14)}$. However, it does not appear that vegetarianism accounted entirely for the differences between SDA and non-SDA men as the proportion of SDA vegetarians decreased over the three decades and yet SDA maintained lower BMI than non-SDA men.

The common predictors of high BMI for both SDA and non-SDA men came from the 'extra' and 'meat' food groups. In addition, low physical activity was associated with higher BMI while eating between meals and dieting to lose weight were linked to lower BMI for both groups. Despite these similarities, the food consumption patterns of the two groups varied markedly. Although SDA men consumed more dessert foods than non-SDA men in 2006, they also tended to consume more of the foods that predicted lower BMI and fewer of the foods that were associated with higher BMI. The lifestyle philosophy of SDA appears to have 'immunised' SDA men from the secular changes that contributed to increases in BMI observed among non-SDA men since 1986. This philosophy advocates physical activity; a regular diet that is rich in grains, fruits, nuts, vegetables and water; avoidance of tea, coffee, rich and highly-refined foods; and abstinence from tobacco, alcohol and other drugs ${ }^{(15)}$. Despite adverse changes in breakfast size, eating between meals and consumption of meat and alcohol (small increases), the findings of the present research support those of Fraser ${ }^{(5)}$ that the majority of SDA men 'adhere to behaviours that may sometimes fall short of the church's recommendations but that still represent a substantial departure from those of others'.

SDA women also tended to consume more of the foods associated with lower BMI and fewer of the foods associated with higher BMI than non-SDA women. In addition, a greater proportion of SDA women were vegetarian and consumed more vegetables and grain foods compared with SDA men. The finding that the diet of SDA women better approximated the Australian Guide to Healthy Eating ${ }^{(16)}$ than that of non-SDA women or SDA men poses a conundrum. Why did SDA women's BMI increase while non-SDA women's BMI remained stable over the 30-year period? The questionnaire design of the present study does not enable an adequate answer to this question, but increases in the portion size of foods prepared outside the home (since the 1980s) may account for the difference ${ }^{(17-19)}$. SDA women may have consumed 'healthy food' more frequently and 'extra foods' less frequently than other women, but they also may have consumed larger portions. Portions sizes are important as 'larger portions mean more calories' and excess energy increases weight ${ }^{(18)}$.

Another explanation may lie in other limitations of our study. The measurement of dietary intake and physical activity employed in these surveys was a major limitation. Dietary assessment based on dietary recall has biases. Respondents, especially women, may choose socially desirable responses (rather than more objectively accurate ones) in an effort to present themselves in a positive light and avoid criticism ${ }^{(20)}$. This may be particularly relevant among SDA women as the SDA church advocates certain lifestyle prescriptions ${ }^{(21)}$. In addition, the SAH questionnaires were changed on four occasions over the 30-year period and further in the 2006 Melbourne survey, making it difficult to maintain continuity in variables that showed associations with BMI. Longitudinal studies and sentinel sites need to develop comprehensive measurement procedures such as FFQ 
that include dietary recall data $(24 \mathrm{~h}$ dietary recall which provides both qualitative and quantitative information on diet) and use these consistently throughout the life of the programme.

Another limitation is the measurement bias of selfreport height and weight used to calculate BMI in 2006. Although self-reported height and weight do correlate highly with BMI calculated from objectively measured heights and weights ${ }^{(22-25)}$, the error in self-reported BMI increases with increasing measured BMI, especially in women, with a trend towards underestimating $\mathrm{BMI}^{(25)}$. It is likely that overweight and obese individuals in our 2006 survey underestimated weight and/or overestimated height, therefore underestimating mean BMI for that year. Validating self-report BMI by obtaining objective measures would provide a correction factor to correct for these biases. A further limitation was the variation in age between SDA and non-SDA, particularly in 1986 and 1988, which may explain the differences in BMI between SDA and non-SDA. However, BMI-lifestyle associations were adjusted age. Furthermore, age differences were found between SDA and non-SDA women where no differences in BMI were found.

A number of spurious BMI associations were found. The consumption of low-energy soft drinks was positively associated with BMI. These drinks may be chosen by individuals with higher BMI as they are lower in energy. In addition, the frequency of vigorous and moderate physical activity was positively associated with BMI for non-SDA men but vigorous physical activity was negatively associated with BMI for SDA men in 2006. BMI differences in the two groups could account for the differential effect of physical activity between SDA and non-SDA men. Physical activity may be performed by non-SDA men to reduce their high BMI. Furthermore, spreads (jams, marmalades, syrup and honey), which were negatively associated with BMI, are energy-dense foods. However, the consumption of spreads may somehow be a marker for a prudent diet as it correlates with the consumption of fruit, vegetables, more frequent and larger breakfast, cereals, bread and legumes. All of these foods were expected to be associated with lower BMI and as outlined earlier each, except for cereals, bread and vegetables, were multivariate predictors of BMI. The reason for these exclusions could be correlations with other foods and this needs to be addressed in future research. Moreover, it is not certain whether the positive associations of low-fat milk and bread rolls have any biological significance or whether they were due to chance, so future longitudinal studies could test these putative relationships.

In summary, it would appear from the main findings that consumption of meat, energy-dense foods and behaviours that may contribute to adverse changes in energy balance (eating between meals, dieting to lose weight and minimal physical activity) result in overweight and obesity. These factors are typical of food consumption, eating behaviour and lifestyle patterns that characteristically make up the 'Western lifestyle'. The dietary guidelines ${ }^{(26)}$ recommend people consume a variety of foods including fruits, vegetables, whole grains, nuts and seeds, small amounts (if any) of sugars, salt, alcohol and saturated fat, and perform regular physical activity. These guidelines reflect the philosophy of the SDA church. The present study has shown that Australians who have embraced the 'Western lifestyle' while moving away from the principles of a 'prudent lifestyle' tend to have higher BMI.

The present results also indicate that in other groups and communities where health is a defining feature of the group, value systems and behaviours relating to diet and lifestyle could be changed ${ }^{(5)}$ :

When the group culture supports a belief in clear benefits, defines standards of behaviour, and then provides skills and opportunities to improve selfefficacy, success becomes more likely. The perception that one's performance is being observed and compared with community values may be motivating. The teaching of the necessary skills becomes easier when one belongs to a supportive and focused society.

The present findings suggest that policies which promote dietary restraint, physical activity and other dietary and lifestyle practices are likely to provide the public with important health benefits. Such policies would help to refocus the dietary and lifestyle habits of industrialised countries from the 'Western lifestyle' to more 'traditional' ways of eating and living, thus reducing the prevalence of obesity.

\section{Acknowledgements}

Financial support was provided by Deakin University, Melbourne, Australia; the Sanitarium Health Food Company, Australia; and Australian Research Council grants awarded to A.W. Statistical assistance was provided by Professor Kai Lo. There were no conflicts of interest to report. L.M.K. was a PhD student conducting the research under the supervision of A.W. Both authors contributed to the manuscript.

\section{References}

1. World Health Organization (1999) Obesity: Preventing and Managing the Global Epidemic. Geneva: WHO.

2. Cameron AJ, Welborn TA, Zimmet PZ, Dunstan DW, Owen N, Salmon J, Dalton M, Jolley D \& Shaw JE (2003) Overweight and obesity in Australia: the 1999-2000 Australian Diabetes, Obesity and Lifestyle Study (AusDiab). Med J Aust 178, 427-432.

3. World Health Organization (2003) Diet, Nutrition and the Prevention of Chronic Diseases. Joint WHO/FAO Expert 
Consultation. WHO Technical Report Series no. 916. Geneva: WHO.

4. Willett WC (1999) Convergence of philosophy and science: The Third International Congress on vegetarian nutrition. Am J Clin Nutr 70, 434S-438S.

5. Fraser GE (2003) Diet, Life Expectancy, and Chronic Disease. New York: Oxford University Press.

6. Lindsted K, Tonstad S \& Kuzma JW (1991) Body mass index and patterns of mortality among Seventh-day Adventist men. Int J Obes 15, 397-406.

7. Lindsted KD \& Singh PN (1998) Body mass and 26 y risk of mortality among men who never smoked: a re-analysis among men from the Adventist Mortality Study. Int J Obes Relat Metab Disord 22, 544-548.

8. Fonnebo V (1992) Coronary risk factors in Norwegian Seventh-day Adventists: a study of 247 Seventh-day Adventists and matched controls. Am J Epidemiol 135, 504-508.

9. Alexander H, Lockwood LP, Harris MA \& Melby CL (1999) Risk factors for cardiovascular disease and diabetes in two groups of Hispanic Americans with differing dietary habits. J Am Coll Nutr 18, 127-136.

10. Australian Bureau of Statistics (2003) Socioeconomic indexes for areas, Australia 2001. http://www.health. nsw.gov.au/public-health/chorep/soc/soc_irsd_lga.htm (accessed February 2007).

11. Commonwealth Department of Health and Aged Care (1999) National Physical Activity Survey. Canberra: DHAC.

12. Calkins BM, Whittaker DJ, Rider AA \& Turjman N (1984) Diet, nutrition intake, and metabolism in populations at high and low risk for colon cancer. Population: demographic and anthropometric characteristics. Am J Clin Nutr 40, 887-895.

13. Haddad EH, Berk LS, Kettering JD, Hubbard RW \& Peters WR (1999) Dietary intake and biochemical, hematologic, and immune status of vegans compared with nonvegetarians. Am J Clin Nutr 70, 586S-593S.

14. Melby CL, Goldflies DG \& Toohey ML (1993) Blood pressure differences in older black and white long-term vegetarians and nonvegetarians. J Am Coll Nutr 12, 262-269.

15. Ministerial Association General Conference of Seventh-day Adventists (1988) Seventh-day Adventists believe... A
Biblical Exposition of 27 Fundamental Doctrines. Hagerstown, MD: Review and Herald Publishing Association.

16. Smith A, Kellett E \& Schmerlaib Y (1998) The Australian Guide to Healthy Eating. Canberra: Commonwealth Department of Health and Family Services.

17. Bryant R \& Dundes L (2005) Portion distortion: a study of college students. J Consum Aff 39, 399-408.

18. Nestle M (2003) Increasing portion sizes in American diets: more calories, more obesity. J Am Diet Assoc 103, 39-40.

19. Young LR \& Nestle M (2002) The contribution of expanding portion sizes to the US obesity epidemic. Am J Public Health 92, 246-249.

20. Hebert JR, Hurley TG, Peterson KE et al. (2008) Social desirability trait influences on self-reported dietary measures among diverse participants in a multicenter multiple risk factor trial. J Nutr 138, 226S-234S.

21. Kristal A, Andrilla C, Koepsell T, Diehr P \& Cheadle A (1998) Dietary assessment instruments are susceptible to intervention-associated response set bias. J Am Diet Assoc 98, 40-43.

22. Bolton-Smith C, Woodward $\mathrm{M}$, Tunstall-Pedoe $\mathrm{H}$ \& Morrison C (2000) Accuracy of the estimated prevalence of obesity from self reported height and weight in an adult Scottish population. J Epidemiol Community Health $\mathbf{5 4}$, $143-148$.

23. Flood V, Webb K, Lazarus R \& Pang G (2000) Use of selfreport to monitor overweight and obesity in populations: some issues for consideration. Aust N Z J Public Health 24, 96-99.

24. Spencer EA, Appleby PN, Davey GK \& Key TJ (2002) Validity of self-reported height and weight in 4808 EPIC-Oxford participants. Public Health Nutr 5, 561-565.

25. Venn AJ, Thomson RJ, Schmidt MD, Cleland VJ, Curry BA, Gennat HC \& Dwyer T (2007) Overweight and obesity from childhood to adulthood: a follow-up of participants in the 1985 Australian Schools Health and Fitness Survey. Med J Aust 186, 458-460.

26. National Health and Medical Research Council (2003) Dietary Guidelines for Australian Adults. Canberra: NHMRC. 